\title{
THE TREATMENT OF HOMOZYGOUS BETA THALASSAEMIA
}

\author{
Major C. M. BATE, M.B., Ch.B., R.A.M.C. \\ British Military Hospital, Dhekelia
}

\section{The nature of the Thalassaemias}

IN a normal adult the main oxygen carrying pigment in the red cells is adult haemoglobin, or $\mathrm{Hb} \mathrm{A}$, and consists of four central haem groups with four attached polypeptide chains. Two of these chains are designated alpha chains and two beta chains. There is a further naturally occurring adult haemoglobin, $\mathrm{Hb} \mathrm{\textrm {A } _ { 2 }}$, which consists of the central haem nucleus, two alpha chains and two delta chains.

In foetal life and in early infancy the physiologically occurring haemoglobin is foetal haemoglobin, $\mathrm{Hb} \mathrm{F}$, which is structurally identical to adult haemoglobin except that the beta chains are replaced by gamma chains.

Thus, the structure of the important physiologically occurring haemoglobins can be summarized as follows:-

$\mathrm{HbA}-\mathrm{Hba}_{2} \beta_{2}$
$\mathrm{HbA}_{2}-\mathrm{Hba}_{2} \delta_{2}$
$\mathrm{HbF}-\mathrm{Hba} \gamma_{2}$

$\mathrm{Hb}$ A comprises 98 per cent of the total haemoglobin in the adult and $\mathrm{Hb} \mathrm{A}_{2}$ the remaining 2 per cent. In the newborn, beta chain production begins to rise steeply at birth and gamma chain production diminishes from just before birth, reaching a minimum at about the age of six months. This is reflected in the fact that $\mathrm{Hb} F$ constitutes 50 to 70 per cent of the total haemoglobin at birth, but diminishes to less than 2 per cent after about the sixth month of life.

The thalassaemias are a group of inherited disorders, characterized by impaired production of one or other of the normally occurring polypeptide chain constituents of adult haemoglobin. This article deals with beta thalassaemia, in which disease synthesis of the beta chain is impaired, while production of alpha chain remains normal.

\section{Inheritance of Beta Thalassaemia}

Homozygous beta thalassaemia is inherited as a codominant characteristic. Individuals heterozygous for the gene suffer from thalassaemia trait, which is usually clinically symptomless, while those homozygous for the gene suffer from the florid haemolytic anaemia, thalassaemia major. Individuals with thalassaemia major are sterile, but those with thalassaemia trait act as the reservoir for the gene within the population.

The geographical distribution of the trait is by no means confined to the Mediterranean littoral, and the disease is common in Arabia, India and Thailand. Banton (1951) undertook a survey of the Cypriot population using a red cell fragility technique and produced a figure of 18 per cent for the carrier rate. It is hoped in the near future to repeat this survey using haemoglobin electrophoresis, when a more accurate assessment of the carrier state may be achieved. 


\section{The pathology of Beta Thalassaemia}

The basic disability in this disease is a failure to produce cells with a normal content of adult haemoglobin F production being an ineffective attempt at compensation. The amount of globin present in each red cell is variable but reduced and this is reflected in a hypochromic blood film showing leptocytosis, target cells and marked anisopoikilocytosis. Due to their extreme thinness the erythocytes show increased resistance to haemolysis by hypotonic salt solutions.

In iron deficiency anaemia the red cells may contain a large amount of colourless globin packing, but this is of course deficient in thalassaemia. Consequently the packedcell volume is better preserved in iron deficiency than in thalassaemia, and the mean corpuscular haemoglobin concentration tends to be lower. The mean corpuscular haemoglobin on the other hand is very much reduced in thalassaemia compared with iron deficiency.

The red cell life span is reduced to seven to twenty-two days. Sturgeon and Finch (1957) showed that the rate of ${ }^{59} \mathrm{Fe}$ uptake by the marrow greatly exceeded its rate of appearance in the red cells in the peripheral circulation a finding which suggests that a major proportion of the erythrocytes are destroyed in the bone marrow before being released into the circulation "ineffective erythropoiesis". Several groups of workers (Bailey and Prankerd 1958, Hillcoate and Waters 1962) have produced results indicating that there are two populations of circulating red cells with differing rates of destruction. The $\mathrm{Hb} F$ produced in this disease is unevenly distributed among the red cells, and those cells containing least haemoglobin F correspond to the more rapidly destroyed group.

The spleen plays a significant part in the production of the anaemia by trapping large numbers of abnormally shaped red cells, and eventually becoming enlarged and congested. At some point secondary hypersplenism develops which exacerbates the anaemia, producing plasma volume expansion, haemodilution and eventually thrombocytopaenia and leucopaenia.

Precipitation of excess unpaired alpha chain on the red cell membrane induces further red cell destruction.

In response to the chronic anaemia there is generalized bone marrow expansion and infiltration of the liver and spleen with erythropoietic tissue, in an attempt to maintain haemoglobin production. The bone marrow comes to extend throughout the long bones, pelvic and pectoral girdles, ribs and the skull. Marrow over-activity is reflected in the presence of nucleated red cells in the peripheral blood.

Gastrointestinal iron absorption rises markedly in this disease, and thalassaemia causes iron loading even in the absence of transfusion. Untreated, the disease produces cardiac failure because of chronic anaemia and plasma volume expansion. The myocardium is further damaged by iron loading, which also eventually produces hepatic cirrhosis, diabetes and endocrine damage. Death in childhood is the usual outcome in the absence of effective therapy.

\section{Clinical Pathological Correlation}

As has been described in the previous section there is gross expansion of the red marrow throughout the skeleton. In the skull this produces bossing, maxillary hyper- 
trophy and prominent malar eminences. The result is a characteristic thalassaemic facies, often referred to as "mongoloid." Figure 1 illustrates a two year old child suffering from homozygous beta thalassaemia. She is stunted, and below the third percentile for height. She has the characteristic facies of the disease, and her abdomen is swollen by an enlarged liver and spleen, a result of infiltration of these organs with erythropoietic tissue. Figure 2 shows her compared with a normal child of the same age. The X-ray changes in this disease are striking (Moseley 1962). Skull X-rays show the diploic space to be widened due to an increased marrow content. Realignment of the internal bony architecture into vertical spicules to prevent the skull tables collapsing produces the characteristic " hair on end" appearance (Fig. 3).

Cortical thinning of the long bones and increase of marrow space produces a characteristic picture of rarefaction. Similar changes in the small bones of the hands and feet give a lace like appearance. Pathological fractures are relatively common and bone age as determined from wrist radiographs appears to be normal in early life, but becomes delayed by the age of six or seven years.

Chest radiographs in a florid case show marked cardiomegally, due to myocardial damage from a combination of iron poisoning and anaemia, and rib expansion due to hyperplastic marrow (Fig. 4).

Some degree of delayed maturation appears to occur in all affected children. Growth is retarded, and this is apparently not explicable on the basis of a low haemoglobin level or growth hormone deficiency (Zaino, Kuo and Roginsky 1969).

The development of secondary sexual characteristics is delayed or absent. It is possible that this is due to damage of the pituitary and gonads by iron deposition.

Sufferers from this disease are particularly prone to infections, which when they occur are associated with a worsening of the anaemia. The complication of hypersplenism has already been described.

The facial deformity mentioned previously may lead to chronic sinus infections, malocclusion and difficulties in intubation during anaesthesia.

Iron loading, as a result of both increased iron absorption and blood transfusion leads to haemosiderosis with eventual liver cirrhosis, diabetes and myocardial damage.

Finally, chronic ulcers over the medial malleoli and an increased incidence of gallstones are seen, as in many other childhood anaemias.

\section{Treatment in British Military Hospital, Dhekelia}

If a thalassaemic patient's $\mathrm{Hb}$ level can be maintained at $10 \mathrm{~g} / 100 \mathrm{ml}$ or above by donor blood, his own bone marrow becomes suppressed. As a result of the marrow suppression, the bony changes of the disease are prevented or arrested. Hypersplenism does not develop, and hepatosplenomegally is reversed. He becomes far less susceptible to recurrent infections, avoids heart failure and grows normally. The quality of life approaches that of a healthy child.

Figure 5 shows the same little girl as in Fig. 1, after six months treatment. She can be seen to have grown by about $5 \mathrm{~cm}$ and become plumper. Her face appears hardly mongoloid and the massive hepatosplenomegally has regressed considerably.

We have found that to maintain a haemoglobin level of $10 \mathrm{~g} / 100 \mathrm{ml}$ or more in homozygous thalassaemic patients it is necessary to transfuse blood every twenty-one 


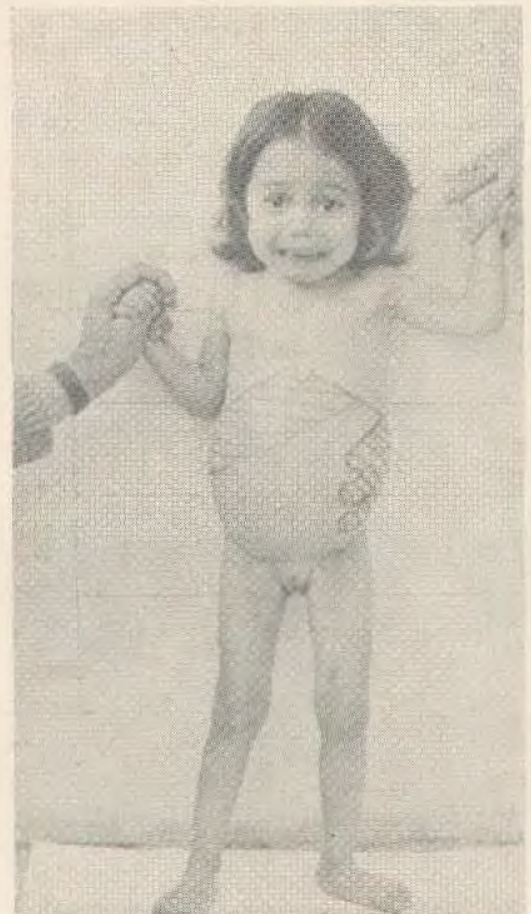

Fig. 1. A two year old child suffering from homozygous beta thalassaemia.

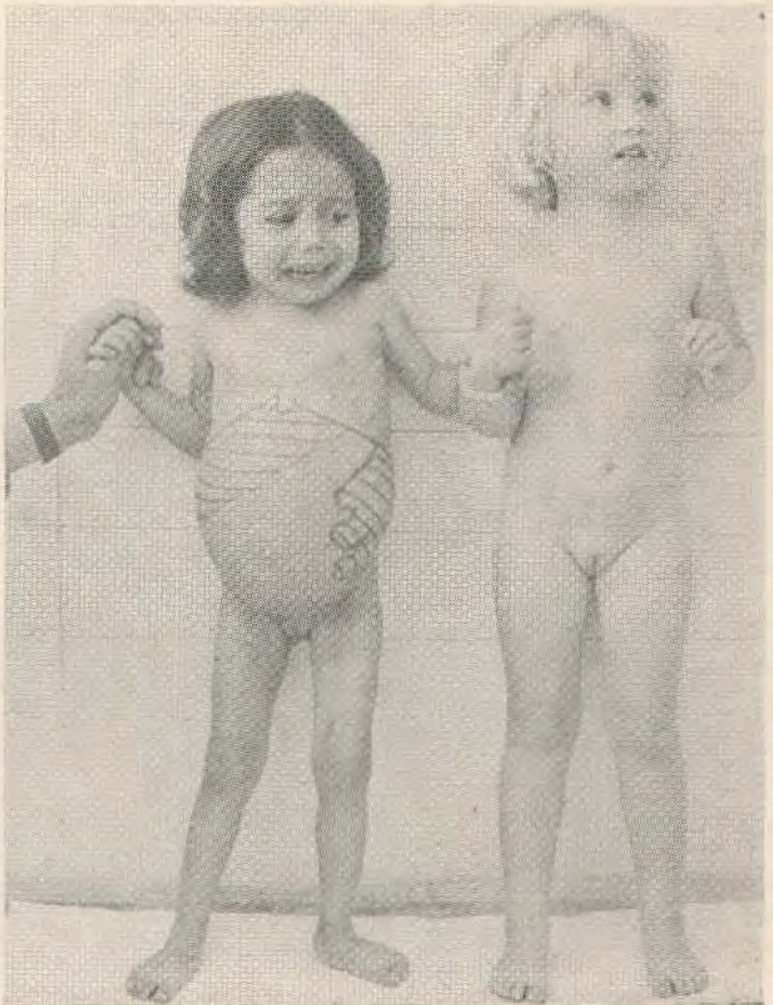

Fig. 2. The same child as in Fig. 1 compared with a normal child of the same age.

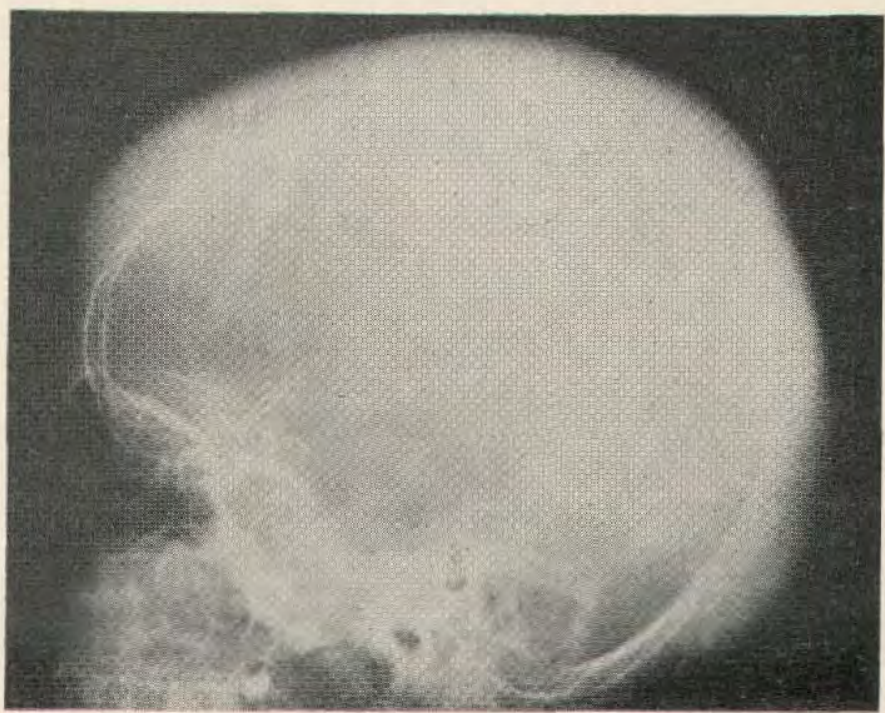




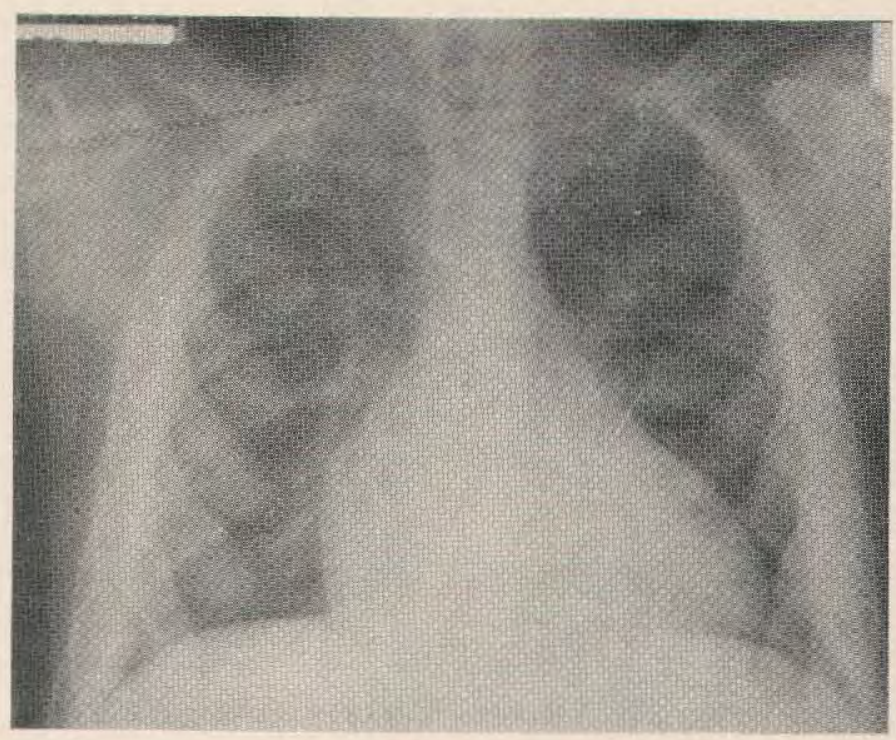

Fig. 4. Chest radiograph.

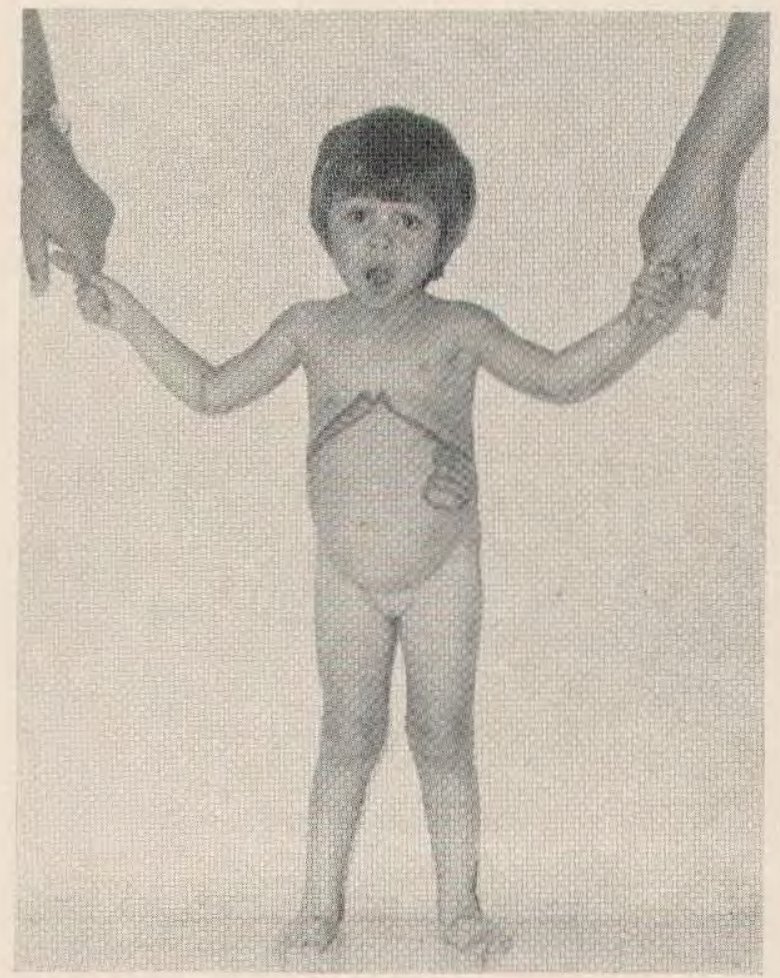

Fig. 5. The same child as in Fig. 1 after six months treatment, 
very demanding of the patients, their relatives and the hospital staff. The supplies of blood are not met from military resources, and the patients are required to produce a civilian donor to contribute a pint of blood for the hospital blood bank before one is released for the use of the patient. Finding donors is a recurring problem for the parents of thalassaemic children, but usually four adult donors, each giving $500 \mathrm{ml}$ of blood every three months can maintain a child for one year. It is vitally important that the transfusion sessions are conducted smoothly and efficiently and as far as possible the same members of the hospital staff are used on each occasion to induce confidence in the patients. Because of the paramount need to preserve peripheral veins, scalp vein needles are used to establish the transfusions, and cut-downs are never performed. Some of our older children who were previously managed elsewhere have extensive cut-down scars at their ankles, elbows and even wrists and sometimes they can be very difficult to transfuse. In a small number of such patients we have attempted to establish a Cimino-Brescia a/v subcutaneous fistula in order to arterialize the peripheral veins of an arm, but so far without success.

When all else fails due to previous cut-downs, obsesity in small patients or in an emergency a plastic cannula inserted into the external jugular vein is a quick, safe and well nigh infallible standby technique.

There are a number of well recognised complications of polytransfusion. Simple urticarial reactions to foreign protein in the transfused serum occur occasionally and are easily abolished by intravenous antihistamines.

Febrile reactions tend to occur in patients who have had many previous transfusions, and are usually due to the patient forming antibodies to donor leucocytes or plasma antigens. Once this trend has become established it can be difficult to deal with but there are reports of the prophylactic efficiency of the use of frozen blood (Korn and Stewart 1971), leucocyte filters and prior washing of donor red cells. In our experience, intravenous hydrocortisone during the transfusion is effective in aborting these reactions.

Sensitization to minor blood groups can occur and it is extremely important to perform accurate genotyping at the start of treatment. This is sometimes one of the causes of a decreasing interval between transfusions.

The risk of transmitting infections by blood transfusion is always possible, and the commonly recognised hazards in this respect are syphilis, malaria, cytomegalorivus (CMV) and serum hepatitis. Malaria was eradicated in Cyprus in 1948, routine serology on donor blood protects against the spirochaete and the CMV is destroyed if the blood is kept for forty-eight hours before use. In the transfusion of approximately 1000 units of blood we have seen only one case of serum hepatitis.

One obvious drawback to a high transfusion regime, is that of haemosiderosis. This can be combated by the use of iron chelating drugs such as desferioxamine (Desferal; Ciba) and diethylene triamine pentacetate (DTPA; Geigy). These agents promote excretion of iron in the urine and faeces. It has been observed that the more heavily iron loaded the patient, the greater the output of iron (Smith 1962, 1964), but unfortunately high levels of iron excretion are not usually maintained on long term treatment.

On theoretical considerations older children would require approximately $6 \mathrm{~g}$ of DTPA with each blood transfusion and an intramuscular injection of about $1 \mathrm{~g}$ of Desferal each day to prevent iron loading, assuming that the response to chelation did 
not decrease with time. It takes about ten years to assess any regime said to lessen mortality from iron loading, so there is at present very little real information available on the efficacy of chelating agents in thalassaemia.

Our practice is to give daily Desferal whenever it is available (it is a very expensive drug) and to use DTPA at the time of transfusion.

Children on a low transfusion regime often become hypersplenic by the age of four to seven years. This is because their red cells are grossly abnormal. The same spleen may leave donor cells unharmed and thus investigation of hypersplenism by following the behaviour of donor ${ }^{51} \mathrm{Cr}$ labelled red cells may return false negative results. At present, our indications for splenectomy are mainly clinical, and include shortening of transfusion intervals in the absence of antibody formation, persistent thrombocytopaenia and leucopaenia and a slump in the percentile chart for height.

We follow splenectomy with long term prophylactic antibiotic therapy to combat the well recognised increase in post-splenectomy infections. Our series includes ten patients who have been subjected to splenectomy with considerable improvement in their clinical condition and a decrease in their transfusion requirements.

Finally, our clinic performs two other important functions. The first of these is that of genetic counselling. Haemoglobin electrophoresis is performed on all members of the patient's family, and the nature and inheritance of the disease explained. All the detected carriers are warned of the risk of marrying another carrier.

The other function is that of diagnosis. The assessment of the amount of $\mathrm{Hb} \mathrm{F}$ is performed by alkali denaturation (foetal $\mathrm{Hb}$ being resistant to denaturation) and $\mathrm{Hb}$ $\mathrm{A}_{2}$ is measured by cellulose acetate electrophoresis.

Heterozygotes show an elevation of $\mathrm{Hb} \mathrm{F}$ of up to 5 per cent and elevation of $\mathrm{A}_{2}$ up to 10 per cent. Homozygotes do not show an elevation of $\mathrm{Hb} \mathrm{A}_{2}$ but show elevation of $\mathrm{Hb} \mathrm{F}$ up to 90 per cent. Both parents, of course, show the electrophoretic pattern of heterozygotes.

\section{Acknowledgement}

My gratitude is due to the many members of the Queen Alexander Royal Army Nursing Corps who by their hard work and enthusiasm, made the running of this clinic possible.

\section{REFERENCES}

Bailey, I. S. and Prankerd, T. A. J. (1958): Studies in Thalassaemia. Brit. J. Haemat. 4, 150.

BANToN, A. H. (1951). A Genetic Study of Mediterranean Anaemia in Cyprus. Amer. J. hum. Genet. 3, 1951 .

Hillcoat, B. L. and Waters, A. H. (1962). The Survival of ${ }^{51} \mathrm{Cr}$ labelled Autotransfused Red Cells in Patients with Thalassaemia. Aust. Ann. Med. 11, 55.

Korn, H. E. T. and Stewart, J. W. (1971). Experience with Frozen Blood for Transfusion. Brit. J. Haemat. 20, 671 .

Moseley, J. E. (1962). The Thalassaemias: Variants and Roentgen Bone Changes. J. Mt Sinai Hosp. 29, 199.

SmITH, R. S. (1962). Iron Excretion in Thalassaemia Major of the Administration of Chelating Agents. Brit. med, J, 2, 1577.

SmITH, R. S. (1964). Chelating Agents in the Diagnosis and Management of Iron Overload in Thalassaemia. Ann. N.Y. Acad. Sci. 119, 776.

Sturgeon, P. and Finch, C. A. (1957). Erythrokinetics in Cooley's Anaemia. Blood 12, 64.

Zano, E. C., Kuo, B. and Roginsky, M. S. (1969). Growth Retardation in Thalassaemia Major. Aun. N.Y. Acad. Sci. 165, 394. 